\title{
A voz é sempre um sonho: conversa com Linda Wise
}

\section{The voice is always a dream: talking with Linda Wise}

Entrevista concedida a Bárbara Biscaro ${ }^{1}$

Em 13 abr. 2014, nas dependências do SESC Cacupé Florianópolis, SC, Brasil 
Linda Wise é atriz, cantora e diretora teatral. Nasceu no Kenya e estudou na Royal Scottish Academy of Music and Drama. Trabalhou com Roy Hart de 1969 até a morte desde em 1975. Membro do Roy Hart Theatre e fundadora do Roy Hart Centre no sul da França. Membro do Panthéâtre, escola francesa que tem o foco no trabalho de voz e corpo do ator, inovando nas técnicas de reconhecimento vocal.

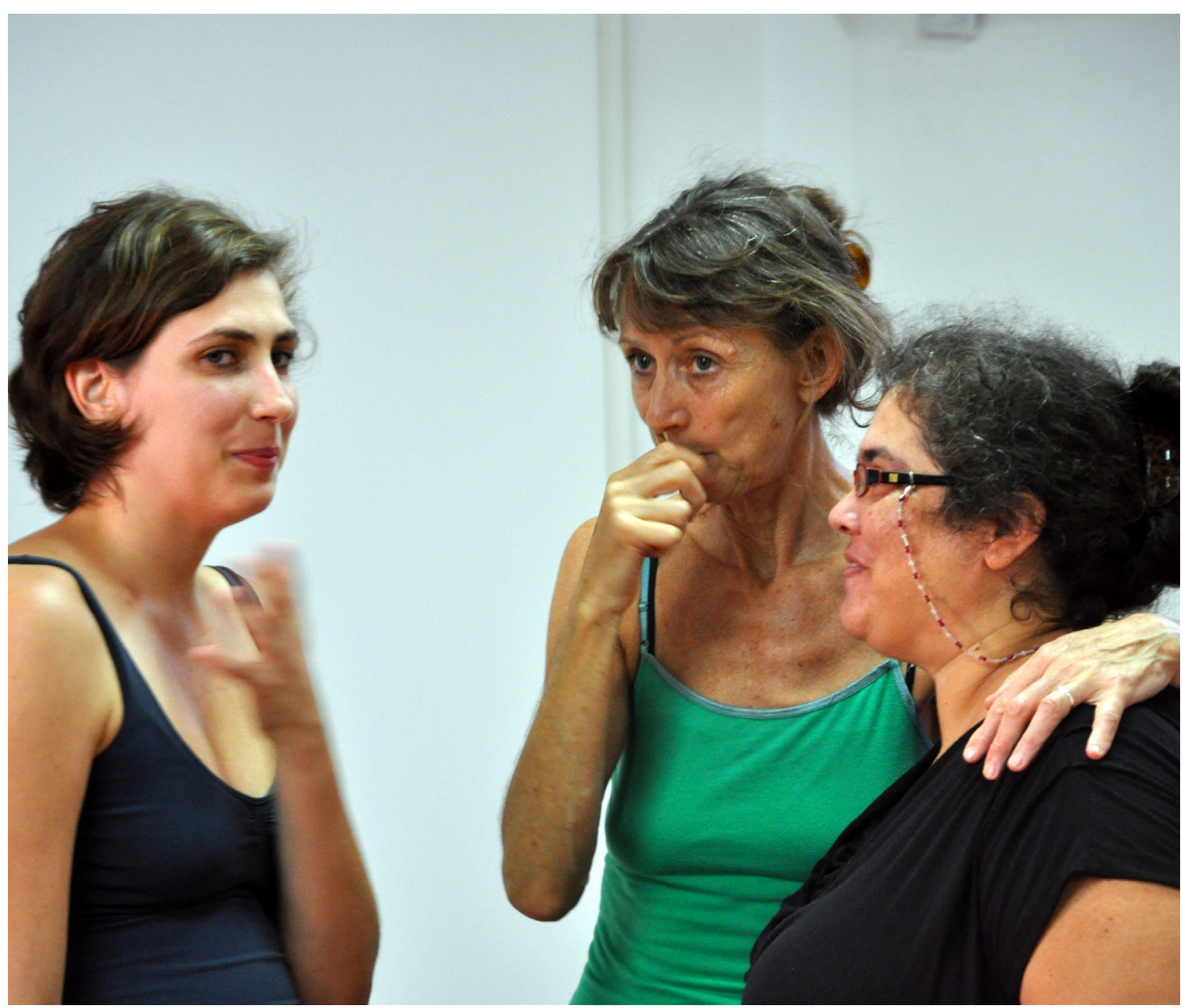

Workshop com Linda Wise.

Da esquerda para a direita: Bárbara Biscaro, Linda Wise e Isabella Irlandini

Foto de Marta Baião em 13 de abril de 2014, nas dependências do SESC Cacupé,

Florianópolis, SC, Brasil.

ISSN: 1414.5731

'Atriz, cantora/pesquisadora vocal. Doutoranda junto ao Programa de E-mail: barbara.biscaro@gmail.con Pós-Graduação em Teatro. Florianópolis, SC, Brasil. Bolsista Capes processo n. 99999.014959/2013-05

\section{Entrevista}

Barbara Biscaro - Linda, por favor, apresente-se para o leitor e conte um pouco sobre o seu trabalho.

Linda Wise - Eu comecei meu trabalho como atriz, bastante jovem, enquanto estava estudando no Royal Conservatoire of Scotland, conheci Roy Hart 2. O encontro com ele e com o Roy Hart Theatre ${ }^{3}$ teve um grande impacto em mim, então decidi escrever minha tese final para a parte acadêmica da universidade sobre o Roy Hart Theatre. Após meus estudos, trabalhei por um curto período como atriz no teatro de repertório e também ensinando, até um momento de crise no qual percebi que algo realmente essencial estava faltando na minha vida. Eu não sabia o que era mas constantemente retornava à minha experiência com o Roy Hart Theatre, então decidi escrever a Roy Hart perguntando se eu poderia ir a Londres trabalhar com ele. Não foi uma decisão fácil, pois sabia que trabalhar com Roy Hart, naquele tempo, demandava um sério envolvimento em sua vida. Ele aceitou. Eu me mudei para Londres, vivi com a companhia e me engajei no trabalho, que naquele tempo, significava aulas de canto, ensaios, longas reuniões, discussões e tentar ganhar também - dinheiro para sobreviver. Isso foi uma pesquisa pessoal e psicológica profunda exigente e intensa sobre a relação entre a voz e a pessoa - e mais tarde sobre a voz em performance.

Em 1974 a companhia começou a se mudar para a França e então, quase um ano depois, Roy Hart morreu em um acidente de carro com sua esposa e outra atriz da companhia. De repente, eu e provavelmente todos os meus colegas, fomos confrontados com a pergunta: vou embora ou continuo fazendo esse trabalho que significa tanto para mim? Eu decidi continuar. Não sabia qual era meu principal interesse, porque antes eu tinha escolhido essencialmente trabalhar com Roy Hart Ele era o mentor/mestre que eu queria seguir. Gradualmente, percebi que não estava interessada apenas em voz pura, o que era o principal trabalho da companhia. Eu queria voltar ao teatro, particularmente para a dança e para o movimento. Muitas coisas aconteceram, mas eventualmente fui convidada a me juntar a Enrique Pardo e seu grupo de pesquisa Pantheatre ${ }^{5}$, o qual começou a investigar a voz estendida em um contexto bastante físico e coreográfico, inspirado por muitas fontes como a dança contemporânea, treinamento autogênico, butho etc... e também o estudo da noção de imagem/produção de imagem. Eu comecei a dirigir bastante, mas novamente me confrontei com uma crise ou momento crucial em meu trabalho como performer. Nós criamos uma versão para quatro vozes da ópera Pagliacci, de Leoncavallo - e o trabalho alcançou muito "sucesso", nós viajamos por cinco anos. Eu estava interpretando o papel de Nedda. Um professor de canto bastante respeitado foi assistir a performance e disse para mim, depois: "Como é possível que você atue

${ }^{2}$ Roy Hart (1926 (Joanesburgo - África do Sul) - 1975 (Nice - França) $\quad{ }^{5}$ Companhia teatral fundada em 1981. - ator, pesquisador vocal e diretor teatral ${ }^{3}$ Companhia teatral fundada por Roy Hart, que promove atividades constantes no campo do teatro e da pesquisa vocal em Malerérgues Enrique Pardo - diretor teatral, performer, pintor e escritor. ${ }_{6}$ Neste texto usarei a palavra estendida, tendo sua grafia correta escrita com s, mas o termo se relaciona ao conceito de extensão vocal França. Para saber mais http://www.roy-hart-theatre.com 
do modo que você atua e cante tão mal. Eu gostaria de lhe oferecer aulas de canto!". A oferta foi de realmente ter aulas de canto clássico, porque a música clássica era o seu domínio artístico. Eu tive uma aula com ele, o que foi uma experiência inesperada que não quis continuar, mas isso abriu uma porta. Ele abriu uma porta na qual percebi que esse tinha sido um território proibido em meu treinamento com - Roy Hart Theatre até aquele momento, e percebi que eu queria saber mais. Então, quando me mudei para Paris com Enrique Pardo, decidi, ok, eu vou estudar bel canto - e não só o canto clássico mas outras formas de canto - e tentar entender qual critério artístico esse homem estava usando quando me disse que eu cantava tão mal. O quê estava faltando? Eu queria entender. Depois de experimentar muitos professores diferentes, achei uma pessoa extraordinária e também professor de bel canto - com o qual ainda tenho aulas. Eu gosto de música clássica porque faz bem à minha alma. Eu gosto da imensa paisagem emocional do repertório - é algo equivalente para mim a fazer Shakespeare - um tipo de linguagem elevada baseada em complexidades profundamente humanas. A partir dessas experiências, percebi que estava realmente interessada na voz em performance, mas na voz em performance relacionada à música. A música propõe outro problema: porque você precisa se relacionar com as demandas da música e com outros musicistas, inspiração, respiração; a emoção não tem mais a mesma liberdade de quando você estava atuando. Nos últimos dez anos, através da minha filha, aconteceu de eu conhecer alguns musicistas jovens que estavam interessados no que eu estava fazendo. Juntos, nós começamos uma colaboração e pesquisa em novas formas de responder e relacionar o vocalista à música e aos músicos. Nós trabalhamos bastante com improvisação, o que me leva a ter um novo ouvido relacionado à como uma performance vocal de canção, texto ou som livre pode estar com/dentro da música e manter a sua criatividade viva.

Eu diria que esse é o meu maior interesse, nesse momento. Acho que se eu não tivesse conhecido esses musicistas, provavelmente não teria tido a chance de entra nesse território e por isso sou muito grata. Aprendi muito. Quando minha filha disse que ela queria se tornar uma cantora, ela disse "eu quero ser uma cantora musicista". Eu pensei bastante, "o quê ela quer dizer com isso?". E percebi que a principal ênfase do trabalho que eu tinha feito com o Roy Hart Theatre, tinha se relacionado até então (o começo do século XXI) com a expressão: expressão pessoal, expansão, extensão, escavação, exorcismo - todos os "ex" - os quais são incrivelmente importantes, mas não estão facilmente presentes junto com as demandas da música.

Bárbara Biscaro - Por que você acha que existiam esses territórios proibidos para a voz no trabalho do Roy Hart Theatre - como as técnicas de canto clássico que você mencionou, por exemplo?

Linda Wise - Eu acho que quando você entra em um novo território, você precisa conhecer e questionar o território antigo. Certamente quando Alfred Wol-

fsohn ${ }^{7}$ começou o seu trabalho, para a maior parte dos estudos em canto na Europa, a referência era o bel canto, com as divisões da voz - homem ou mulher, baixo, barítono, soprano, mezzosoprano, coloratura etc.- ele se formou com essas referências. Quando ele começou a ter uma visão da voz a qual ele chamou "a voz humana e livre" essa voz não poderia seguir os mesmos critérios e classificações. Eu magino que ele pensou "ok, não podemos continuar treinando do mesmo modo". Ele estava vindo de um lugar de profundo trauma, dos horrores da Primeira Guerra Mundial, os quais literalmente o assombravam e que ele instintivamente sentiu que devia exorcizá-los. Eu também acho que suas reflexões vieram em um momento da história no qual enormes barreiras estavam sendo quebradas e exploradas psicologicamente, especialmente por Freud, Lacan e mais tarde, Carl Jung. O movimento da psique humana exigia essa explosão, essa redefinição do quê é um ser humano, e toda a ideia da mulher achar o seu lado masculino e um homem achar seu lado mais feminino - os conceitos de animus e anima. Alfred Wolfsohn estava consciente disso e trabalharia com esses conceitos. Então era realmente necessário romper o treinamento, reinventar, re-imaginar os "vocalizes" que foram usados por diversas gerações. Alfred Wolfsohn foi um filósofo, um profundo pensador no confronto com os problemas com sua própria voz - quebrada em seu trauma pós-guerra - e mais tarde trabalhando com cantores que tinham problemas.

Ele começou a investigar o conceito de onde vêm os sons humanos, e não só a fim de cultivar a beleza - bel canto. Durante a querra ele ouviu o que a voz humana era capaz de emitir em stress. Ele podia ouvir pessoas que ainda tinham voz depois de emitir sons terríveis. Então ele realmente queria saber do quê a voz humana é feita, fisicamente, antes do puro instrumento de canto, antes de se tornar um instrumento para a fala. Isso era o material cru. Também ele acreditava firmemente que cantar, do modo como ele entendia isso, era conhecer a si mesmo. Uma jornada introspectiva para dentro, que significava não só procurar pela beleza do que você é capar de fazer, de emitir, mas a parte mais sombria, mais escura e obscura de si mesmo. Nesta jornada a voz se torna diferente; eu hesitaria dizer melhor, mas diferente. Por exemplo, ele sofreu de tuberculose no fim da sua vida e quase não conseguia falar [Linda dá um exemplo do som da voz dele] e naquele momento ele começou uma investigação sobre o som quebrado - o que era um som quebrado, o que era uma voz quebrada, que é muito diferente de um som quebrado - de onde isso vem. Não é só uma questão de perder o apoio [respiratório] (o que frequentemente seria a resposta de um cantor clássico), existiam razões psicológicas mais profundas, mas também havia espaços ali. Então ele estava trabalhando nis so - assim é como eu entendo quando leio seus textos e quando ouço o material sonoro que nós temos daquela época - era uma pesquisa constante para dentro da condição humana.

Roy Hart veio de outro lugar, porque ele não era um musicista; ele era um vocalista incrivelmente talentoso e um ator brilhante. Ele conheceu o trabalho de Alfred Wolfsohn enquanto estava estudando na RADA ${ }^{8}$ - o mito nos conta - que 
enquanto Roy Hart estava ensaiando o papel de Otelo em um espetáculo do RADA ele foi fazer uma aula de canto com Wolfsohn, e disse a ele: "Eu me sinto desincorporado ${ }^{9}$ neste papel, eu não consigo entender como esse homem mata a mulher". Alfred Wolfsohn respondeu: "Ok, a gente precisa trabalhar nisso, vou te levar ao lugar no qual você sente que poderia me assassinar". Roy Hart falaria sobre essa aula como um confronto profundo, porque ele sentiu que chegou exatamente naquele ponto de querer matar o seu mestre. A gente pode projetar todos os tipos de coisas que poderiam ter acontecido nessa aula - mas posso imaginar a energia, toda a fúria, a escuridão, toda a cequeira que levou Otelo a matar, provavelmente tudo isso emergiu na aula. Roy Hart decidiu: "Ok, termino meus estudos no RADA - mas deixo o teatro e esse é o trabalho da minha vida". A pesquisa de Roy Hart era incrivelmente ligada a essas emoções com as quais o ator trabalha. Era um trabalho de profunda expressão, sempre ligado ao canto, no sentido de um som sustentado tanto que ele pessoalmente desenvolveu essa extraordinária extensão vocal.

No final dos anos 1960 ele começou a ficar conhecido, e pessoas como Peter Brook, Grotowski, Aldous e Julian Huxley vieram ao seu espaço e também compositores contemporâneos - era um momento realmente importante de reconhecimento do valor do trabalho e também de Roy Hart como um vocalista único. Henze, Stockhausen, e outros compositores menos conhecidos, escreveram para a sua voz, mas provavelmente, para mim, o mais importante foi seu maravilhoso e em última análise trágico encontro com Peter Maxwell Davies, que escreveu Eight songs for a mad king $^{10}$ para ele. Essa peça foi composta com Roy Hart - e eu digo com Roy Hart porque Roy improvisou e Peter Maxwell Davies compôs com base em suas improvisações. Esta peça é uma pedra angular da música-teatro contemporânea, e eu realmente acho que foi um ponto de mudança também para a ópera contemporânea, porque era provavelmente a primeira vez que um compositor escreveu para tal tipo de voz. A música não é realmente tão complicada, mas ainda exige precisão musical. A esposa de Roy Hart, Dorothy Hart ${ }^{11}$ - (uma pianista e linda cantora), 0 treinou para que ele pudesse incorporar as demandas da música, atuação e voz estendida nessa peça e em outras sucessivas.

Por que eu digo que isso foi uma tragédia? Porque essa peça teve um imenso impacto na cena inglesa, tanto no mundo do teatro quanto no mundo da música. Quando a peça foi convidada a circular, houve uma repentina e definitiva separação entre Roy Hart e o compositor. Eu nunca realmente entendi o que aconteceu - eu tentei pesquisar com todos que lembram - mas parece que envolvia dinheiro e o fato de Roy Hart sentir que ele tinha contribuído para a composição e não estava sendo respeitado como o artista que ele era, e Peter Maxwell Davies, o compositor estava recebendo todo o crédito.

Isso foi triste - também para o trabalho vocal naquela época - porque Peter Maxwell Davies quis compor para a companhia e poderia ter sido possível, naquele momento, que muitos dos cantores desenvolvessem sua relação com a música. A separação foi um tanto violenta. Uma separação similar aconteceu com Henze e

10 Peça estreada em 1969

" Dorothy Hart (1926-1975), integrante do Roy Hart Theatre. outros compositores. Foi pouco depois dessas separações que nós mudamos para a França e Roy Hart morreu no acidente de carro, portanto, não houve solução para essa nova relação entre o trabalho da voz estendida com a música contemporânea. Nós organizamos um encontro, no final dos anos 1970, no qual muitos compositores contemporâneos foram convidados a ir a Malérargues, para ouvir o trabalho vocal. Uma peça emergiu deste encontro com Paul-Heinz Dietrich, um compositor da Alemanha Oriental, que foi inspirado pela performance de Enrique Pardo de Calling for Pan. Ele queria que Enrique fosse o solista em uma composição baseada no livro de Kafka - A Metamorfose - com Enrique fazendo o inseto. Era um trabalho bastante difícil - especialmente físico - ele começava a performance em uma mala então você pode imaginar a compressão do corpo e a dificuldade de cantar e ouvir.

Bárbara Biscaro - Isso é algo que você vê frequentemente? Eu digo, quando compositores de música e pesquisadores vocais se encontram, às vezes não existe um olhar real para o corpo do performer - existe pouca escuta entre essas áreas muitas vezes.

Linda Wise - Sim.

Bárbara Biscaro - Eu gostaria de saber se depois de todas essas mudanças como a introdução da música em seu trabalho - como você vê as conexões entre o trabalho de cantores e atores. É bastante claro que em seu trabalho existe um fluxo entre essas ações (cantar, falar, atuar). Como você vê este caminho do "entre"?

Linda Wise - Eu acho que provavelmente se poderia dizer que o quê faz o trabalho é a pessoa. Então quando trabalho, o primeiro passo é enxergar onde a força da pessoa está - se é um cantor, por exemplo, como abrir sua capacidade de atuar. E como tentar achar o caminho onde o performer realmente faz a osmose - o que significa muito trabalho individual e também um desejo do performer de entrar em outro território. Quantos atores eu ouço dizer "eu quero cantar"? Você poderia dizer que a razão maior do porque pessoas procuram um trabalho vocal é porque eles querem "cantar" - e esse desejo de cantar, vem também porque frequentemente pessoas não se dão oportunidade de cantar, ou de treinar o canto. Eles não percebem que é um trabalho, há um lado bastante natural, mas é também um duro trabalho de artesão, assim como atuar.

Por exemplo, quando trabalho com alguém como Annie Murath ${ }^{12}$ no Chile, provavelmente uma das minhas mais talentosas alunas, ela está absolutamente neste "território do entre". Quando ela canta uma canção, não vejo diferença entre ela como atriz, performer e sua emissão vocal. Eu vejo alguém como Annie, que veio com uma voz treinada no bel canto e abandonou seu repertório de canto porque não conseguia se encontrar ali. Ela migrou para o teatro e achou a si mesma um pouco mais na atuação - Quando a conheci era como se ela estivesse nesse 
"território do entre", você poderia dizer que era o seu território, entre música, emoção e voz - mas a sua voz parecia não a seguir até lá. Eu me lembro claramente da primeira vez que ouvi a sua voz, eu podia ouvir todo o potencial, mas era como se a sua voz estivesse presa dentro de uma caixa do treinamento, ou algo parecido. Gradualmente, com o passar dos anos, ela não perdeu o seu treinamento, mas a sua atitude mudou - e também o seu repertório e isso também é muito importante. Ela se moveu bastante dentro do repertório de Kurt Weill, música Latino Americana - e composições de Violeta Parra, algumas das quais são, de fato, incrivelmente contemporâneas - ela fez uma versão de El Gavillon que é totalmente atuar-cantando. A integração era dela - era uma escolha sua. Como artista, ela precisou colocar esses dois mundos juntos, ela precisava e encontrou outro som. O que você poderia dizer é que ela encontrou a "sua voz" - mas eu não sei, eu acho que ela já havia achado a sua voz, mas não tinha conseguido integrar os dois mundos. De algum modo, em nosso trabalho juntas, ela foi capaz de achar a integração. Ela nunca julgou nada e correu grandes riscos - como se tivesse dito: "Ok, estou entrando nesse mundo e vou o mais fundo que puder para fazer isso, se tiver que gritar, eu vou realmente gritar". Nós nunca estivemos naquele ponto no qual ela diria - "como vou usar isso?" - foi uma necessidade que integrou aquilo em sua arte.

Bárbara Biscaro - Isso é realmente algo que eu penso; em minha visão, por exemplo, o trabalho vocal é algo muito pessoal. Cada pessoa tem uma potencialidade, todas as pessoas são diferentes; às vezes as pedagogias vocais enfrentam um paradoxo: você tem que dar o mesmo treinamento para todos, mas os percursos são muito pessoais - cada um/uma escolhe o seu próprio caminho, os tipos de aulas que freqüenta, como conduzir uma prática, como construir uma história vocal. Você dá muitas aulas; eu gostaria de saber sua opinião sobre esse desafio e paradoxo entre ensinar tantas pessoas e observar os potenciais caminhos individuais de cada um/uma.

Linda Wise - Basicamente, treinamento eu dou a pouquíssimas pessoas. Nos workshops abertos eu tento receber todos que vêm, mas só recentemente eu tenho dado workshops tão grandes. Quando você vem para a América Latina, esse é o único modo das pessoas poderem pagar para conhecer o trabalho. De outra maneira, como costumávamos trabalhar - um a um, três professores com dez alunos, trabalho individual sem fim - as pessoas, agora, não conseguem mais pagar por isso. Esta integração, o trabalho de ir mais fundo, é também, como você diz, bastante pessoal. Primeiro de tudo, o professor com quem você escolhe trabalhar é uma decisão incrivelmente pessoal e fazer esta escolha é parte do aprendizado. Eu frequentemente digo às pessoas: "Você pode vir a Malèragues, claro que você vai conseguir um treinamento incrivel de todos que estão ali, e então, se você realmente quiser ir mais fundo, você terá que fazer escolhas, pois nem todo mundo ensina do mesmo modo". A transmissão e o processo de acompanhamento é algo muito interessante e sutil. Você também tem que ter coragem de reconhecer que talvez você chegou ao fim de uma jornada com alguém - tanto como "pupilo" quanto como "professor".
Por exemplo, para alguém como você, eu não diria: "você deve seguir este ou aquele tipo de trabalho" Eu diria: "isso é interessante, e talvez te dê alguma abertura"; mas a partir daí, é sua tarefa integrar isso em seu trabalho. Conheci essa cantora contemporânea da Alemanha - ela tinha treinamento em canto contemporâneo uma carreira internacional e bem sucedida na música - mas houve momentos em que ela dizia: "Eu quero ir até aí e trabalhar esse som em particular, o qual preciso em meu repertório". E eu respondia: "Olha, eu farei o que eu posso, mas não posso garantir que eu possa lhe fazer chegar exatamente no que você quer" - porque eu acredito fortemente na intenção por trás do som. Você talvez encontre um professor que diga "Ok, venha. Para fazer esse som você ergue seu palato mole e então respire desse modo, etc". Essas escolas científicas de pesquisa são interessantes, há muito o que aprender a partir desses estudos, porque você pode chegar ao som. Mas para mim, o problema é: você alcança o som, mas, o som está integrado na voz do cantor e mais importante, na imaginação do cantor? Porque se você chega ao som, ele precisa ser revisitado, precisa ser incluído na sua memória corporal, na sua psique e imaginação. Você não pode se contentar em chegar lá - você precisa se conectar com o som, algo que se pode chamar de "incorporação ${ }^{13 "}$ e não apenas imitação.

Bárbara Biscaro - A última pergunta se relaciona com meu principal interesse de pesquisa no momento, as conexões entre a escuta e o trabalho vocal Gostaria de ouvir você falar um pouco sobre isso, como você trabalha essa questão em sua prática.

Linda Wise - Eu poderia dizer que meu treinamento inicial foi totalmente baseado na escuta. Roy Hart costumava dizer: "Eu não tenho um método", então qual era o método? Escutar vozes e vozes, sem parar. Horas e horas de escuta - de outras vozes, aulas, conversas na rua. Então a pessoa começa a ouvir e diferencia muitos tipos de coisas - onde há tensão, onde está a quebra, onde está a perda da conexão, onde está a ansiedade. E toma tempo - é experiência de uma vida - ao mesmo tempo é algo disponível para todos nós.

Através da escuta e trabalhando sobre si mesmo, eu acredito, você constrói um léxico. Você tem todos esses sons e pode entender - como este som está ressoando ali e não lá, como abri-lo mais (se você está trabalhando como professor) - como posso aprofundar o timbre, abrir os harmônicos, etc. Como professor, certamente, mas como performer também há muita escuta, e primeiro, eu acho, certo mimetismo. Nós sabemos que nossas cordas vocais se movem em empatia quando estamos realmente escutando, portanto, se você está realmente escutando, você está fazendo os sons também.

Eu sempre digo, ouçam a todos, assim é que vocês vão aprender mais, mas deve ser de modo concentrado, uma escuta ativa. Existe também a questão do re-

${ }_{13}^{13}$ Embodiment

${ }^{14}$ Brigitte Cirla è cantora e atriz, fundadora do grupo Voix Polyphoni-

ques. Para saber mais ver: http://www.voixpolyphoniques.org 
pertório e imaginação, se você nunca ouviu um repertório, ou se você nunca ouviu certos tipos de música, é frequentemente mais difícil de aprender. A tradição oral - algo que Brigitte Cirla ${ }^{14}$ trabalha bastante e é fantástico - é a parte mais natural de cantar. Eu acho que o "treinamento" de canto deveria dar muito mais ênfase a isso. Nem todos nasceram perfeitamente afinados, mas a maioria de nós é sortuda o suficiente para ouvir e sentir as vibrações, assim como experimentamos no workshop ${ }^{15}$, quando cantamos na direção dos corpos de nossos colegas - e aí está toda uma área de pesquisa que eu espero que você abra em seu doutorado.

Recebido em 15/06/2014

\footnotetext{
15 Workshop dado por Linda no evento Vértice Brasil 2014 - em FloPara saber mais www.verticebrasil.net 